\title{
Evaluation of hepatitis A, B, and C serology in patients with cirrhosis and intensive alcohol consumption
}

\author{
Sezgin Vatansever, ${ }^{1}$ Zehra Betul Pakoz, ${ }^{2}$ Belkis Unsal ${ }^{1}$ \\ ${ }^{1}$ Department of Gastroenterology, Katip Celebi University, Ataturk Training and Research Hospital, İzmir, Turkey \\ ${ }^{2}$ Department of Gastroenterology, Tepecik Training and Research Hospital, İzmir, Turkey
}

\begin{abstract}
OBJECTIVE: The objective of this study was to evaluate the serology of hepatitis $A, B$, and $C$ in patients with cirrhosis and intensive alcohol consumption.

METHODS: We retrospectively reviewed the viral serology results of 817 patients with cirrhosis and intensive alcohol consumption who presented to the Gastroenterology Clinic of Atatürk Training and Research Hospital of Izmir Katip Çelebi University between April 2008 and December 2017. The diagnosis of cirrhosis was based on clinical and biochemical evaluations and imaging results. Patients consuming absolute alcohol $40 \mathrm{~g} /$ day for $>10$ years were included and those who quit drinking $\geq 15$ years ago were excluded.
\end{abstract}

RESULTS: Of all the patients, 806 (98.7\%) were positive for anti-HAV IgG, 159 (19.5\%) for HBsAg, and 32 (3.9\%) for antiHCV. Genotyping was performed in 13 patients. Genotype 1 was detected in 10 patients (1a, one patient; 1b, nine patients) and genotype 3 in three patients. Of the patients with $\mathrm{HBV}, 10.0 \%$ had $\mathrm{HBeAg}$ and $7.6 \%$ had anti-delta. One-hundred and two (12.5\%) patients had HCC, and of these, six (5.9\%) were HCV-positive and $53(52.0 \%)$ were HBsAg-positive.

CONCLUSION: Patients with cirrhosis and intensive alcohol consumption have an increased hepatitis $\mathrm{B}$ and $\mathrm{C}$ prevalence. Patients with chronic viral hepatitis with alcohol habit are at a higher risk for HCC. Therefore, patients with cirrhosis and intensive alcohol consumption should be screened for hepatitis $\mathrm{B}$ and $\mathrm{C}$.

Keywords: Alcohol, cirrhosis, Hepatitis A, Hepatitis B, Hepatitis C.

Cite this article as: Vatansever S., Pakoz Z.B., Unsal B. Evaluation of hepatitis A, B, and C serology in patients with cirrhosis and intensive alcohol consumption. North Clin Istanb 2018;5(2):109-113.

A lcohol-related mortality and morbidity is an important public health problem worldwide. In the USA half of the liver-related deaths are due to alcohol [1]. In Europe, the most common cause of advanced hepatic disease is alcohol [2]. In Germany, $18 \%$ of the population aged $>18$ years consumes $>20-30 \mathrm{~g}$ of alcohol per day [3]. Alcohol is responsible for $5.9 \%$ of all deaths world- wide [4]. Intensive alcohol consumption is prevalent in alcoholic chronic HCV infection, with high seroprevalence of $\mathrm{HCV}$ detected in alcoholic individuals [5-8]. Alcohol consumption combined with hepatitis B presence results in the progression of chronic liver disease $[9,10]$. Alcohol combined with hepatitis $\mathrm{B}$ or $\mathrm{C}$ presence has a synergistic effect for developing HCC [11].

Received: February 06, 2018 Accepted: April 25, 2018 Online: May 22, 2018

Correspondence: Dr. Sezgin VATANSEVER. Department of Gastroenterology, Katip Celebi University, Ataturk Training and Research Hospital, İzmir, Turkey

Phone: +90 23224444 44-28 07 e-mail: sezginvatansever19@gmail.com

(c) Copyright 2018 by Istanbul Provincial Directorate of Health - Available online at www.northclinist.com 
The present study aimed to determine hepatitis A, B, and $\mathrm{C}$ seroprevalence in patients with cirrhosis and intensive alcohol consumption.

\section{MATERIALS AND METHODS}

\section{Patients}

We retrospectively reviewed 817 patients with cirrhosis and intensive alcohol consumption who presented to our clinic between April 2008 and December 2017. Clinically, cirrhosis was defined as the presence of jaundice, ascites, and hepatic encephalopathy. Regarding the laboratory findings, PT prolongation and the presence of decreased albumin indicated cirrhosis. Radiologically, the presence of nodular liver, splenomegaly, and ascites indicated chronic liver disease. Patients consuming alcohol $40 \mathrm{~g} /$ day for $>10$ years were included in the study ( $>80 \mathrm{~g} /$ day in 800 patients). Individuals who quit drinking $\geq 15$ years ago were excluded from the study. Patients were asked about the amount and type of alcohol they consumed and the duration (years) of their alcohol habit. The time and amount of smoking were expressed as daily number of packs multiplied by the duration. The height and weight of the patients were measured. For patients in whom HBV and HCV were detected, HCV-RNA or HBV-DNA was investigated using the real-time PCR method. The assessment was based on the serologic profile at the time of admission to the hepatology outpatient clinic. HBsAg was measured using the chemiluminescence method with the fully automated Johnson \& Johnson macro ELISA instrument .

HCC diagnosis was made using dynamic imaging methods (MRI and CT) for patients with early arterial staining and venous washout.

\section{Statistical analysis}

Statistical analyses were performed using the IBM SPSS Statistics 22 program. Statistics are reported as means, ranges, and percentages. The normal distribution suitability of the variables was studied using analytical methods. Patient distribution was done using Pearson's chisquare test and Fisher's exact test for categorical variables and Student's t test for independent samples. KruskalWallis and Mann-Whitney $U$ tests were used for samples with non-normal distribution. One-way ANOVA was used to assess multiple groups for normal distributions in continuous variables. Bonferroni correction was used to determine $\mathrm{p}$ value in post-hoc tests. When the
ANOVA results were evaluated post-hoc, the Scheffe test was used for homogenous distribution and Dunnett's $C$ test for nonhomogeneous data. Statistical significance was set at $\mathrm{p}<0.05$.

\section{RESULTS}

We evaluated 817 patients with cirrhosis and intensive alcohol consumption. Table 1 summarizes the demographical and clinical data of the patients.

Of the patients, 806 (98.7\%) were positive for antiHAV IgG, 159 (19.5\%) for HBsAg, and 32 (3.9\%) for anti-HCV. One patient was negative for HCV-RNA. Genotyping was performed in 13 patients. Genotype 1 was detected in 10 patients ( $1 \mathrm{a}$, one patient; $1 \mathrm{~b}$, nine patients) and genotype 3 in three patients. One patient was positive for both hepatitis $B$ and $C$.

Of the patients with $\mathrm{HBV}$, delta antibody was detected in $7.2 \%$ and $\mathrm{HBeAg}$ was positive in $10.0 \%$. Table 2 summarizes the characteristics of patients with hepatitis $B$ and C infection.

TABLE 1. Demographic profiles and clinical characteristics of the study group

Patients characteristics

$\mathrm{n}=817$

Age

$55.8 \pm 9.9$

$\operatorname{Sex}(\mathrm{F} / \mathrm{M})$

$13 / 804$

Alcohol consumption time (year)

$27.6 \pm 9.4$

Alcohol consumption (g/day)

$149 \pm 62$

Recent 10 year alcohol consumption (g/day) $\quad 165 \pm 83$

Kind of alcohol

Beer

$22.4 \%$

Raki

$68.5 \%$

Wine

$7.6 \%$

Whiskey

$1.6 \%$

Smoking rate (\%)

$90.0 \%$

Smoking consumption time (year)

$32(5-62)$

Smoking (packs*year)

$35(3-110)$

BMI $\left(\mathrm{kg} / \mathrm{m}^{2}\right)$

$27.5 \pm 5.4$

Serology

Anti HAV IgG

$806(98.7 \%)$

HBsAg

$159(19.5 \%)$

Anti HBc IgG

$448(54.8 \%)$

Isolated Anti $\mathrm{HBC}$ IgG

$91(11.1 \%)$

Anti HBs

$248(30.4 \%)$

Anti HCV 
TABLE 2. Comparison of HBV+alcohol, HCV+alcohol and alcohol groups

\begin{tabular}{lcccc} 
Patients characteristics & $\begin{array}{c}\text { Alcohol+HBV } \\
\mathrm{n}=159\end{array}$ & $\begin{array}{c}\text { Alcohol+HCV } \\
\mathrm{n}=31\end{array}$ & $\begin{array}{c}\text { Alcohol } \\
\mathrm{n}=628\end{array}$ & $\mathrm{p}$ \\
\hline Age & $55 \pm 9$ & $60 \pm 10$ & $56 \pm 10$ & 0.03 \\
Age at the time of first drinking alcohol & $29.4 \pm 9.8$ & $32.5 \pm 13.5$ & $28.1 \pm 9.0$ & 0.071 \\
Sex (F/M) & $2 / 157$ & $0 / 31$ & $11 / 616$ & 0.698 \\
Alcohol consumption time (year) & $26.3 \pm 8.9$ & $29.1 \pm 10.7$ & $27.8 \pm 9.4$ & 0.236 \\
Alcohol consumption (g/day) & $136 \pm 56$ & $154 \pm 57$ & $152 \pm 63$ & 0.049 \\
Recent 10 year alcohol consumption (g/day) & $137 \pm 59$ & $156 \pm 58$ & $172 \pm 87$ & $<0.0001$ \\
Smoking rate (\%) & $93.5 \%$ & $92.9 \%$ & $89.2 \%$ & 0.436 \\
Smoking consumption time (year)* & $35(8-60)$ & $40(20-60)$ & $32(5-62)$ & 0.007 \\
Smoking (packs*year)* & $32.5(3-100)$ & $50(10-110)$ & $35(3-100)$ & 0.039 \\
BMI (kg/m²) & $25.8 \pm 5.9$ & $25.7 \pm 4.1$ & $27.8 \pm 5.4$ & 0.147 \\
Presence of HCC at admission & $53 / 159(33.3 \%)$ & $6 / 31(19.4 \%)$ & $41 / 627(6.5 \%)$ & $<0.0001$ \\
Anti HAV IgG & $97.9 \%$ & $100 \%$ & $98.7 \%$ & 0.833 \\
Anti Delta & $7.2 \%$ & - & - & - \\
HBeAg & $10.0 \%$ & - & - & \\
Log HBV-DNA & $4.3 \pm 2.3$ & - & - & \\
Log HCV-RNA & - & $5.5 \pm 1.6$ & - & \\
\hline
\end{tabular}

*Smokers only

One-hundred and two (12.5\%) patients had HCC on admission. Of these patients, six (5.9\%) were HCVpositive and $53(52.0 \%)$ were $\mathrm{HBsAg}$-positive. Among anti-HBs positive patients, $12(4.83 \%)$ had HCC on admission.

Multivariate regression analysis showed that age and $\mathrm{HBV}$ infection were independently related to HCC occurrence.

\section{DISCUSSION}

A population-based multicenter study performed in Turkey found HBsAg, anti-HAV total, and anti-HCV seroprevalences of $4.0 \%, 93.2 \%$, and $1 \%$, respectively [12]. According to this data, hepatitis $\mathrm{B}$ and $\mathrm{C}$ seroprevalence was higher in our patients with cirrhosis and intensive alcohol consumption than in the Turkish population. Figure 1 presents a comparison of data from the normal population and subjects in our study.

The reason for admission among patients with cirrhosis is the symptoms emerging as a result of progressing cirrhosis. The HBV group, despite less alcohol use $(p=0.0001)$, had earlier onset of symptoms $(p=0.03)$ and higher probability of presenting with HCC ( $\mathrm{p}=0.0001)$. There are many studies evaluating hepatitis $\mathrm{B}$ and $\mathrm{C}$ sero-

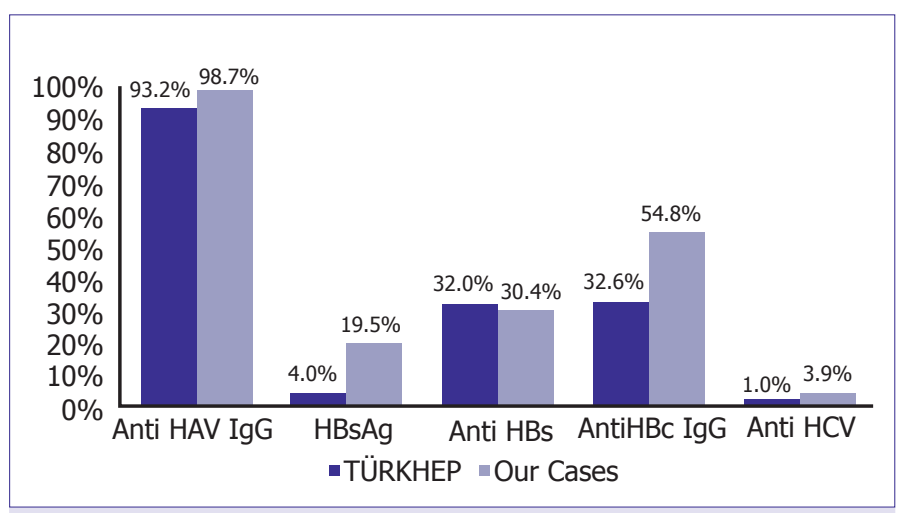

FIGURE 1. Comparision of viral hepatitis seroprevalences between alcoholic cirrhotic patients and normal population.

prevalences in subjects with alcohol intake. The results of 25 studies publishing HCV prevalence in patients with $\mathrm{HCV}$ were pooled and resulted in a mean prevalence of $16.3 \%$ [13]. However, this study found a higher result as it involved European subjects. In a study by Tekin et al. in 2015, anti-HAV total, $\mathrm{HBsAg}$, and anti-HCV positivity for patients with alcoholic cirrhosis were 91.5\%, 16.3\%, and $8.2 \%$, respectively. Bruno et al. determined hepatitis C seroprevalence of $15 \%$ in alcoholic individuals [14]. In a further study, anti-HCV and $\mathrm{HBsAg}$ were found to be $55.6 \%$ and $15.7 \%$, respectively [15]. Although varying 
numbers have been reported across studies, all had higher hepatitis B and hepatitis $\mathrm{C}$ seroprevalences in subjects with alcohol intake than in the normal population. In our study, the results were high, similar to those reported in previous studies. In the HBV group, anti-delta and $\mathrm{HBeAg}$ frequency were comparable with that in the normal population in Turkey. Among HCV patients, genotype 3 was detected in 3/13 (23.1\%) patients. Genotype 3 is more common in some geographical regions and is more frequent among IV drug abusers. In Turkey, genotype 1B (about 90\%) is the dominant HCV genotype. The result may be incidental.

A meta-analysis by Hutchinson et al. demonstrated in 15,000 patients with chronic HCV infection [16] that heavy alcohol intake (210-260 g/week) increased the risk of advanced fibrosis and cirrhosis. Another study found an increased cirrhosis risk in patients with hepatitis B and C and alcohol intake [17].

Alcohol intake increased hepatic necroinflammatory activity and fibrosis in HBsAg-positive patients. A study by Larkin et al. in transgenic mice in 2001 demonstrated that alcohol intake combined with hepatitis B increased the risk of developing cirrhosis and HCC [18].

HCV-related hepatic disease progression and HCC risk were evaluated in a study in Japanese moderate $(<80$ $\mathrm{g} /$ day) and heavy (>80 g/day) drinkers. Compared with nonalcohol drinkers, the risk of developing cirrhosis and HCC was 1.5-2.5 times higher [19]. There are other studies showing an increased HCC risk in patients with viral hepatitis and alcohol intake $[18,20,21]$.

A study by Cortes et al. in 2013 found a high risk of developing HCC in patients with hepatitis B and heavy alcohol consumption [15].

A study in Turkey investigating the risk factors for HCC determined HBV and HCV infections with alcohol intake in $18(8.6 \%)$ of 207 patients with HCC. The proportion of those taking alcohol only was $7.2 \%$ [22]. In our study, $102(12.5 \%)$ patients had HCC at the time of admission. Of these patients, $52.0 \%$ were positive for $\mathrm{HBsAg}$ and $5.9 \%$ for $\mathrm{HCV}$.

In this study, the clinical, laboratory, and radiological findings indicated cirrhosis in all patients. The increased risk of HCC and cirrhosis associated with alcohol intake combined with hepatitis B or hepatitis $C$ is also described in the literature. Therefore, viral hepatitis serology should be checked in all patients with cirrhosis and intensive alcohol consumption, and a closer monitoring of patients with positive results may be appropriate.
The limitation of our study was its retrospective and cross-sectional design. Thus, it is not conclusively known whether the risk of developing HCC remains high following the cessation of drinking, particularly in patients with chronic viral hepatitis. It may be more appropriate to seek the answer to this question in cohort studies. The other limitation is that we were unable to distinguish alcoholic cirrhosis from alcoholic steatohepatitis. Although laboratory and clinical findings are similar in these situations, determining fibrosis with biopsy is helpful for discrimination. We were unable to obtain biopsies because of the laboratory findings of the patients .

In conclusion, both the risk of encountering chronic viral hepatitis and the prevalence of chronic viral hepatitis is higher in patients with cirrhosis and alcohol intake. There is a higher risk of progressing to advanced liver disease and developing HCC in chronic viral hepatitis.

\section{CONCLUSION}

Hepatitis C and B seroprevalences in patients with cirrhosis and intensive alcoholic consumption were higher than that in the normal population. The proportion of our patients with HCC at the time of first admission was also high. Our data is consistent with other results in the literature. Therefore, serologic tests for hepatitis B and C should be performed in patients with cirrhosis and intensive alcohol consumption, and they should be vaccinated as necessary. Studies should be performed to determine whether the risk of HCC remains high even after quitting alcohol.

Conflict of Interest: The authors declare no conflict of interest.

Financial Disclosure: The authors declared that this study has received no financial support.

Authorship contributions: Concept - S.V.; Design - S.V.; Supervision - B.U.; Materials - S.V.; Data collection \&/or processing - S.V.; Analysis and/or interpretation - S.V., B.P.; Writing - B.P.; Critical review - S.V., B.P., B.U.

\section{REFERENCES}

1. Maher JJ. Alcoholic liver disease. In: Feldman M, Friedman LS, Sleisenger $\mathrm{MH}$, editors. Gastrointestinal and Liver Disease Vol II. Philadelphia: Saunders; 2002. p. 1375-91.

2. European Association for the Study of Liver. EASL clinical practical guidelines: management of alcoholic liver disease. J Hepatol 2012;57:399-420. [CrossRef]

3. Mueller S, Millonig G, Seitz HK. Alcoholic liver disease and hepatitis C: a frequently underestimated combination. World J Gastroenterol 2009;15:3462-71. 
4. World Health Organization. Global status report on alcohol and health. Available at: http://www.who.int/substance_abuse/publications/ global_alcohol_report/en/.Accessed Apr 26, 2018.

5. Anand BS, Currie S, Dieperink E, Bini EJ, Shen H, Ho SB, et al; VAHCV-001 Study Group. Alcohol use and treatment of hepatitis C virus: results of a national multicenter study. Gastroenterology 2006;130:160716. [CrossRef]

6. Bhattacharya R, Shuhart MC. Hepatitis C and alcohol: interactions, outcomes, and implications. J Clin Gastroenterol 2003;36:242-52. [CrossRef]

7. Costentin CE, Trabut JB, Mallet V, Darbeda S, Thépot V, Nalpas B, et al. Management of hepatitis $C$ virus infection in heavy drinkers. Alcohol Alcohol 2013;48:337-42. [CrossRef]

8. de Oliveira LC, Buso AG, de Oliveira AT, Arantes CA, Borges LV, Valente SR. Prevalence of hepatitis B and hepatitis $C$ markers in alcoholics with and without clinically evident hepatic cirrhosis. Rev Inst Med Trop Sao Paulo 1999;41:69-73. [CrossRef]

9. Hassan MM, Hwang LY, Hatten CJ, Swaim M, Li D, Abbruzzese JL, et al. Risk factors for hepatocellular carcinoma: synergism of alcohol with viral hepatitis and diabetes mellitus. Hepatology 2002;36:1206-13.

10. Stroffolini T, Cotticelli G, Medda E, Niosi M, Del Vecchio-Blanco C, Addolorato $\mathrm{G}$, et al. Interaction of alcohol intake and cofactors on the risk of cirrhosis. Liver Int 2010;30:867-70. [CrossRef]

11. Donato F, Tagger A, Chiesa R, Ribero ML, Tomasoni V, Fasola M, et al. Hepatitis $\mathrm{B}$ and $\mathrm{C}$ virus infection, alcohol drinking, and hepatocellular carcinoma: a case-control study in Italy. Brescia HCC Study. Hepatology 1997;26:579-84. [CrossRef]

12. Tozun N, Ozdogan O, Cakaloglu Y, Idilman R, Karasu Z, Akarca US, et al. A nationwide prevalence study and risk factors for hepatitis A, B, C and D infections in Turkey. Hepatology 2010;52 Supp1:697.

13. Novo-Veleiro I, Calle Cde L, Domínguez-Quibén S, Pastor I, Marcos M, Laso FJ. Prevalence of hepatitis $\mathrm{C}$ virus infection in alcoholic patients: cohort study and systematic review. Alcohol Alcohol 2013;48:564-9.

14. Galperim B, Cheinquer H, Stein A, Fonseca A, Lunge V, Ikuta N. Prevalence of hepatitis $\mathrm{C}$ virus in alcoholic patients: role of parenteral risk factors. Arq Gastroenterol 2006;43:81-4. [CrossRef]

15. Cortes VF, Taveira A, Cruz HM, Reis AA, Cezar JS, Silva BS, et al. Prevalence of Hepatitis $B$ and $C$ virus infection among alcoholic individuals: importance of screening and vaccination. Rev Inst Med Trop Sao Paulo 2017;59:e47. [CrossRef]

16. Hutchinson SJ, Bird SM, Goldberg DJ. Influence of alcohol on the progression of hepatitis $\mathrm{C}$ virus infection: a meta-analysis. Clin Gastroenterol Hepatol 2005;3:1150-9. [CrossRef]

17. Stroffolini T, Cotticelli G, Medda E, Niosi M, Del Vecchio-Blanco C, Addolorato $\mathrm{G}$, et al. Interaction of alcohol intake and cofactors on the risk of cirrhosis. Liver Int 2010;30:867-70. [CrossRef]

18. Larkin J, Clayton MM, Liu J, Feitelson MA. Chronic ethanol consumption stimulates hepatitis $\mathrm{B}$ virus gene expression and replication in transgenic mice. Hepatology 2001;34:792-7. [CrossRef]

19. Khan KN, Yatsuhashi H. Effect of alcohol consumption on the progression of hepatitis $C$ virus infection and risk of hepatocellular carcinoma in Japanese patients. Alcohol Alcohol 2000;35:286-95. [CrossRef]

20. Fukushima W, Tanaka T, Ohfuji S, Habu D, Tamori A, Kawada N, et al. Does alcohol increase the risk of hepatocellular carcinoma among patients with hepatitis $C$ virus infection? Hepatol Res 2006;34:141-9.

21. Uetake S, Yamauchi M, Itoh S, Kawashima O, Takeda K, Ohata M. Analysis of risk factors for hepatocellular carcinoma in patients with $\mathrm{HBs}$ antigen- and anti-HCV antibody-negative alcoholic cirrhosis: clinical significance of prior hepatitis B virus infection. Alcohol Clin Exp Res 2003;27:47S-51. [CrossRef]

22. Uzunalimoğlu O, Yurdaydin C, Cetinkaya H, Bozkaya H, Sahin T, Colakoğlu S, et al. Risk factors for hepatocellular carcinoma in Turkey. Dig Dis Sci 2001;46:1022-8. [CrossRef] 